Resumen por el autor, W. E. Sullivan.

La anatomía de una mano sindáctila.

La mano estudiada presenta una unión completa de los dedos mediante membranas y una fusión parcial de los elementos óseos. Los carpianos están reducidos a seis, los metacarpianos a cuatro y las falanges a siete. Los músculos más modificados son los flexores largos; los lumbricales, que faltan; los interóseos, de los cuales hay solamente uno. Las inserciones de los flexores largos han emigrado proximalmente hasta transformarse en flexores de la muñeca. Las modificaciones musculares y óseas están relacionadas parcial, no completamente. Elementos fibrosos tienden a sustituir a los elementos óseos ausentes. La condición vascular, aunque no es la ordinaria, pudiera presentarse en una mano normal. La distribución de los nervios está relacionada directamente con otras modificaciones. La extirpación de los dos dedos intermedios aumentaría la utilidad de la mano. 


\title{
THE ANATOMY OF A SYNDACTYLOUS HAND
}

\author{
W. E. SULLIVAN \\ University of Wisconsin \\ ONE FIGURE
}

The hand in question may be referred to as brachydactylous as well as syndactylous, for there is a reduction of one phalanx in each digit in addition to the webbing and fusion. It is the right hand of a male laborer about forty years old. The left hand is normal. Nothing is known of the family history.

The general shape of the hand is sufficiently indicated by the radiograph. The volar surface is unbroken and there is no indication of separate digits. The thenar and hypothenar eminences are well marked. The thenar eminence is slightly reduced, but the hypothenar would equal the average normal elevation. The skin is thick, creased, and calloused and indicates a serviceable hand.

On the dorsal surface the presence of separate digits is suggested by three well-defined nails. These three nails are fairly indicative of the internal condition. The x-ray shows part of a fourth digit and suggests that there are five terminal phalanges. Dissection shows more clearly that there are five terminal phalanges.

In the discussion it seems best to refer to the digits as the radial, radial intermediate, ulnar intermediate, and ulnar in the order indicated. From the relations found on dissection it was interpreted that the radial digit represents the first and second digits, the radial intermediate, the ulnar intermediate, and the ulnar represent the third, fourth, and fifth digits, respectively. 


\section{MODIFICATION OF THE BONES}

The bones of the forearm show little if any modification. The distal end of the radius is slightly enlarged.

Six carpal elements are present. These are interpreted as representing the ossa naviculare and lunatum in the proximal row, the multangulum majus, capitatum, pisiforme, and triquetrohamatum in the distal row. The position and articulations of the several bones are seen in the radiograph. It may be pointed out that the distal end of the navicular overlaps the volar surface of the greater multangular. The os multangulum minus is absent. The os capitatum is greatly modified and corresponds to the proximal portion of the normal bone. The condition of the last two bones is in line with the general modification of the second and third digits. The os pisiforme is much flattened and somewhat larger than is usual. The os triquetrohamatum is the name given to the large medial bone of the distal row. Its position and articulations as well as its size and shape indicate that it is the result of the fusion of the triquetrum and hamatum. The hamulus is much reduced.

The metacarpals show a considerable range of modification. The radial metacarpal is normal at its proximal end, but at the distal end presents two large articular surfaces, somewhat separated by a ridge, for the phalanges, and a small volar facet for a sesamoid.

The metacarpal of the radial intermediate digit is represented proximally by a small, ovoid, bony element. This bony element is imbedded in a wedge of fibrous tissue which has its base against the capitate and which, at its distal end, is connected with the phalanx by a round ligament more than a millimeter in diameter.

The two medial metacarpals are fused at their proximal ends. At the distal end each presents an articular surface for its phalanx.

In addition to the loss of one phalanx in each digit, there are one or two interesting modifications. The radial phalanx is large and irregular and is formed by the fusion of two terminal phalanges. The proximal end has two distinct articular surfaces, well separated by a groove. The more medial lies some- 
what dorsad. On the dorsal surface the individuality of the two phalanges is clearly seen. The fact that the radial digit is equal in length to the other digits naturally suggests that there has been a fusion of the proximal and distal phalanges rather than the loss of a phalanx. There is nothing in the structure of the phalanx to indicate that this has been the case.

The proximal phalanx of the radial intermediate digit represents only the distal end of a phalanx, but, as already pointed out, it is joined to the metacarpal by a heavy ligament. The proximal phalanx of the ulnar intermediate digit is fused with its metacarpal and is somewhat longer than the other phalanges.

\section{MODIFICATION OF THE MUSCLES}

The forearm is well developed and at the elbow is but slightly smaller than its fellow. The muscles inserting on the radius and ulna are not modified. Those having a more distal insertion may be best discussed individually.

The palmaris longus, palmaris brevis, and flexor carpi ulnaris are normal.

The thenar muscles as a group are fairly well developed and arise from the lateral half of the transverse carpal ligament. The deeper fibers insert into the metacarpal. The more superficial fibers separate into two bundles to insert in part mediad and in part laterad on the volar surface of the base of the phalanx. The innervation suggests the absence of the adductor pollicis.

The hypothenar muscles are better developed than the thenar group. They arise from the pisiforme and medial half of the transverse carpal ligament and insert into the metacarpal and proximal phalanx. All of the hypothenar muscles are present.

But one interosseous muscle is present. It is a poorly developed volar interosseous of the ulnar digit.

The flexor digitorum sublimis is relatively small and ends in two small tendons which insert into the capitate and hamate. In addition, the tendons of the sublimis and profundus converge to form a common tendon of insertion into the distal row of carpals and the bases of the metacarpals. It acts only as a flexor of the wrist-joint. 
The flexor digitorum profundus is of normal size. It goes over for the most part into the common tendon with the sublimis, but sends one tendon to the proximal phalanx of the ulnar digit. This tendon gives flexion and adduction at the metacarpophalangeal joint. The muscle as a whole acts as a flexor of the wrist-joint.

The lumbricals are absent.

The flexor carpi radialis inserts into the radial metacarpal.

The extensor carpi radialis longus inserts on the dorsum of the base of the radial metacarpal. The extensor carpi radialis brevis is absent.

The extensor digitorum communis has two tendons of insertion. The lateral tendon inserts on the phalanx of the radial digit. The medial tendon lies in the plane of the ulnar intermediate digit and for the most part inserts into the metacarpal. In addition it sends a slip to the radial intermediate metacarpal and a larger slip which attaches rather loosely to the dorsum of the ulnar metacarpal.

The abductor pollicis longus inserts into the lateral surface of the base of the radial metacarpal. Just dorsal to this is the insertion of the extensor pollicis brevis.

The extensor pollicis longus has an origin corresponding to the combined origin of itself and the extensor indicis proprius. It inserts into the terminal phalanx of the radial digit well toward the lateral margin.

The extensor digiti quinti proprius inserts into the proximal phalanx of the ulnar digit.

\section{VARIATIONS IN THE ARTERIES}

The ulnar and interossei vessels supply the forearm and hand. The radial artery is absent, while the volar interosseous is much enlarged. Such a condition might occur in an otherwise normal hand, and it is perhaps unwise to correlate it with the other factors. 
There is but one volar arch which is formed largely by the ulnar, but which is completed by a perforating branch from the volar interosseous. The terminal branches of the volar interosseous supply the dorsum of the wrist and hand.

\section{NERVES}

The cutaneous distribution of the nerves showed nothing beyond the usual range of variation. On the dorsum of the hand they may be traced farther distally on the terminal phalanx than is usually possible on a normal hand.

\section{MOVEMENTS AT THE SEVERAL JOINTS}

The radiocarpal and carpometacarpal are biaxial joints. The movements in the former are normal. In the latter flexion and extension are possible through a range of about $80^{\circ}$, but abduction and adduction are modified in several ways. The fusion of the bones in the two medial digits as well as the general webbing restrict the movements. Splitting the hand and removing all of the ulnar intermediate digit except the base of the metacarpal added greatly to the range of forced movement.

\section{SUMMARY}

Muscular and osseous modifications are partially but not completely correlated. Fibrous elements tend to take the place of absent bony elements.

The vascular condition, while unusual, might occur in a normal hand.

The distribution of the nerves is directly correlated with the modification of the other structures.

\section{LITERATURE CITED}

Pritzane, W. Beiträge zur Kentniss der Missbildungen des menschlichen Extremitätenskelets. Morphologische Arbeiten, Band 8.

Schwalbe, E. 1906 Die Morphologie der. Missbildungen des Menschen und der Tiere. Jena. 


\section{PLATE 1}

\section{EXPLANATION OF FIGURE}

Radiograph of a right hand. In the text the digits are referred to as radial, radial intermediate, ulnar intermediate, and ulnar. 
PLATE 1

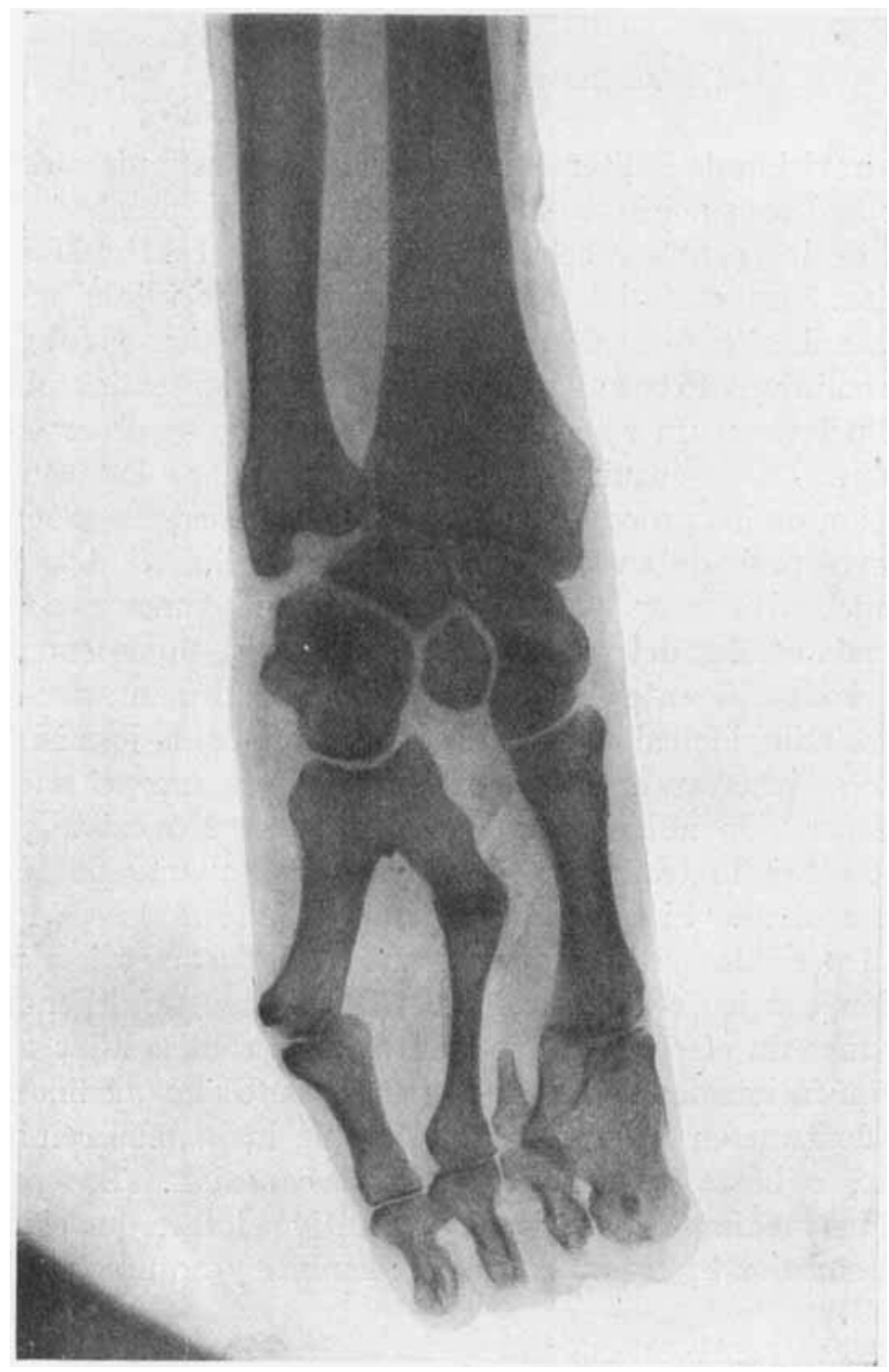

THE ANATOMICAL RECORD, vol. 23 , No. 2 